\title{
A memória de um universo histórico na escrita de Agualusa.
}

\author{
Ana Cristina Pinto Bezerra ${ }^{1}$
}

RESUMO: Analisa-se o percurso memorial construído na obra $O$ Vendedor de passados (2004) de José Eduardo Agualusa, escritor angolano, em que a memória atua como um "agente da estrutura". Revelando o passado histórico da sociedade angolana como uma "metaficção historiográfica", nos dizeres da estudiosa Inocência Mata (2006), entre as genealogias criadas por Félix Ventura como vendedor de passados e as identidades reveladas dos personagens que compõem essa narrativa.

ABSTRACT: Analyze the route memorial built on the work The seller of the past (2004) by José Eduardo Agualusa, angolan writer, in which the memory acts as an "agent of the structure" to revealing the past history of the Angolan society as a "historiographic metafiction" in words of the scholar puts it (2006) between the genealogies created by Felix Ventura as a salesman of the past and revealed the identities of the characters that make up this story.

PALAVRAS-CHAVE: Memória; Construção, Agualusa, metaficção historiográfica.

KEYWORDS: Memory; Construction, Agualusa, historiographic metafiction.

A narrativa do escritor angolano José Eduardo Agualusa, $O$ vendedor de passados (2004), ${ }^{2}$ configura um panorama em que a

\footnotetext{
${ }^{1}$ Mestranda em Letras pela Universidade Federal do Rio Grande do Norte com área de concentração em Literatura Comparada, tendo como título da pesquisa: "A tessitura da memória em O vendedor de passados de José Eduardo Agualusa”.
}

2Todas as citações retiradas do texto literário são encontradas em: AGUALUSA, José Eduardo. O vendedor de passados. Gryphus. Rio de Janeiro, 2004. 
estética literária dialoga incessantemente com o contexto social. Tendo em vista que o enredo conjuga de forma alegórica um personagem albino, denominado de Félix Ventura, que se intitula vendedor de passados, um genealogista que se especializa em "fabricar" memórias no espaço da Luanda "pós-colonização", inserido na busca da população burguesa da cidade de adquirir "um nome que ressoe a nobreza e a cultura" (AGUALUSA, 2004, p. 17).

Desse modo, a memória alarga o estrato social ao projetar o olhar sobre o passado de Angola, tanto no cerne do momento de colonização, em que as marcas deste periodo ainda são sentidas pelos personagens que querem se enquadrar no modelo "branco" de ser, cujo reflexo demarca o que Fanon assevera como o "negro escravo de sua negrura" (1983, p. 11), quanto no período de "pós-colonização" 3 no tocante à guerra civil no espaço angolano, um confronto devastador que durou vinte e cinco anos intervalados por diminutos periodos de paz. No entanto, a memória projeta tal contexto social numa relação dialética com o aparato formal da obra, de maneira que o modo como a ficção é construída entrelaça-se ao âmbito social numa linguagem proficua, mergulhada na ironia mordaz do autor sobre a conjunção tempo e espaço, revelando uma escrita de olhar contundente em que a memória compreende um dos elementos centrais do texto. De modo que a memória pode ser tomada aqui como um "agente da estrutura", nas palavras de Antonio Candido (1976), ao estabelecer-se como constituinte da estrutura literária e não apenas como referente ou matéria para a criação do texto em si. Assim, a memória age sobre o narrador, uma osga (espécie de lagartixa), pelo fato dele se compor como uma espécie de reencarnação que busca entender os fatos acontecidos na sua vida de outrora para compreender melhor o

3 O termo "pós-colonização" não é tomado aqui de maneira a entender que se operou realmente de forma completa a descolonização, o "pós" caracteriza-se pela tentativa de periodizar um momento, apesar da dificuldade de se precisar isso. 
presente, e sobre os personagens que em seus relatos tentam edificar suas identidades através de "frestas" do passado rememorado, ou pelas memórias compradas do vendedor de passados. Além disso, a ação memorial no texto conflui também tempo e espaço, já que se constitui um tempo indefinido nas sucessivas voltas ao passado que se traduzem, igualmente, em travessias espaciais motivados pela ação memorial.

Nessas circunstâncias, é que se reflete sobre a leitura de $O$ vendedor de passados (2004) como uma metaficção historiográfica, a partir da explicação de Inocência Mata sobre romances que recebem tal denominação: “[...] são romances que se apropriam de personagens e acontecimentos históricos, não para simplesmente celebrar o passado, mas para o utilizar como veículo de uma reflexão sobre a própria condição presente do país e sua projecção futura” (2006, p. 57-58). Na medida em que a obra em questão demonstra um pensamento reflexivo sobre o passado para tecer considerações mais críticas sobre o presente de uma sociedade que se refugia numa memória "comprada" para esconder as marcas de décadas de colonização. É assim, que pode-se observar os clientes de Félix Ventura:

Procurava-o, explicou, toda uma classe, a nova burguesia. Eram empresários, ministros, fazendeiros, camanguistas, generais, gente, enfim, com o futuro assegurado. Falta a essas pessoas um bom passado, ancestrais ilustres, pergaminhos. Resumindo: um nome que ressoe a nobreza e a cultura. Ele vende-lhes um passado novo em folha. Traça-lhes a árvore genealógica. Dá-lhes as fotografias dos avôs e bisavôs, cavalheiros de fina estampa, senhoras do tempo antigo. (AGUALUSA, p. 17)

O fato de a narrativa apresentar como personagem protagonista "um homem que traficava memórias" (AGUALUSA, p. 16) 
revela uma sociedade presa, "ainda", ao sentimento colonizador com o receio de denunciá-lo ou de enxergá-lo com maior clareza. De modo que, os clientes de Félix Ventura preferem tomar a ilusão construída por esse como espelho da realidade, e a defenderem como se realmente tivesse vivido, o que subjaz a crítica de Agualusa a uma sociedade que não consegue absorver o seu presente e se reinscrever nele a ponto de melhorá-lo por compreendê-lo.

Como muito bem exemplifica o personagem Ministro que após ter negociado um "bom" passado para com Félix Ventura, como insigne descendente de Salvador Correia, "ilustre carioca que em 1648 libertou Luanda do domínio holandês" (AGUALUSA, p. 120) chega a defender intensamente essa "nova" versão de seu passado como se realmente não houvesse qualquer referência a seu respeito que não fosse essa:

Quem teve a estúpida idéia de mudar o nome do liceu?! Um homem que expulsou os colonialistas holandeses, um combatente internacionalista de um país irmão, um afro-descendente, que deu origem a uma das mais importantes famílias deste país, a minha. [...] Então sou descendente de Salvador Correia, caramba!, e só agora sei disso. Muito bem. A minha senhora vai ficar feliz. (AGUALUSA, p. 121)

Não obstante, é nessa busca de reconstruir o passado, nas genealogias criadas e vividas, que se chega às vivências dolorosas de um espaço devastado pelos conflitos políticos, marcas essas, submergidas diante do discurso que sustenta uma falsa ordem social. $\mathrm{Na}$ verdade, denota-se a tentativa de compreensão da dimensão do presente, uma construção determinada pelo medo, pelo cenário de imprecisão diante do destino político do país. Assim, é que um dos clientes de Félix Ventura, o forasteiro José Buchmann declara: "Acredito que sim, tão carentes de um bom passado andamos nós todos , e em particular aqueles que por essa triste pátria nos desgovernam, governando-se" (AGUALUSA, p. 108). 
Nesse sentido converge-se a visão das ruínas de Luanda, imagem que compõe o cenário de guerra e a tentativa de reconstrução. Sendo que o presente representa essa ação que a osga observa ao esgueirar-se pala casa de Félix Ventura, acompanhando os rumos desse "barco cheio de vozes", constatando, inclusive, as mudanças ocorridas na cidade através das transformações na própria casa de Félix Ventura: "Naquela época, antes da independência, ainda não havia o muro alto, a separar o jardim do passeio, e o portão estava sempre aberto" (AGUALUSA, p. 26).

A imagem da capital angolana é tecida pelo próprio autor em entrevista à revista Ler - Livros e Leitores ${ }^{4}$, quando dissertava sobre outro romance seu, no caso Barroco tropical (2009), em que o espaço remonta novamente o olhar sobre Luanda ao asseverar que: "[...] Luanda sempre foi isso, ou seja, uma cidade que foi crescendo sobre as ruínas do passado. Desde a época colonial. Os portugueses também destruíram muito. O que está a acontecer agora é a dar-se continuidade a essa destruição" (2009, p. 36). Tal imagem conjuga-se com o olhar ficcional de $O$ vendedor de passados (2004) desse espaço híbrido sob o signo do aniquilamento na voz do próprio "fabricante de memórias", Félix Ventura:

Luanda está cheia de pessoas que parecem muito lúcidas e de repente desatam a falar línguas impossiveis, ou a chorar sem motivo aparente, ou a rir, ou a praguejar. Algumas fazem tudo isso ao mesmo tempo. Umas julgam que estão mortas. Outras estão mesmo mortas e ainda ninguém teve coragem de as informar.[...] É uma feira de loucos, esta cidade, há por aí, por essas ruas em escombros, por esses musseques em volta,

${ }^{4} \mathrm{~A}$ entrevista completa encontra-se disponivel em: http://www.afonsopacheco.com/joomal/images/phocadownload/barro co_tropical/01.05\%20Revista\%20Ler\%20$\% 20$ Entrevista.pdf?ml=5\&mlt=system\&tmpl=component. Acesso 10 mar. 2011. 
patologias que ainda nem sequer estão catalogadas. (AGUALUSA, p. 162)

Nessa releitura ficcional do passado, cabe analisar a construção de alguns personagens da obra que recuperam esse momento na trama a fim de reinterpretá-lo de acordo com as necessidades de compreensão do presente, o que já foi visto segundo a explicação de Inocência Mata (2006) como uma metaficção historiográfica. Desse modo tem-se, por exemplo, o personagem Pedro Gouveia que adentra na trama ao obter uma nova identidade criada por Félix Ventura, passando a viver o nome de José Buchmann (um angolano) como se jamais houvesse sido outro que não esse, segundo a própria percepção da osga:

[...] vejo que José Buchmann não é José Buchmann, e sim um estrangeiro a imitar José Buchmann. Porém, se fechar os olhos para o passado, se o vir agora, como se nunca tivesse o tivesse visto antes, não há como não acreditar nele - aquele homem foi José Buchmann a vida inteira. (AGUALUSA, p. 65)

A imagem de tal personagem, revelada no climax do romance sob a identidade de Pedro Gouveia, guarda uma data histórica do contexto de guerra angolano referente ao ano de 1977. Nesse ano, uma parcela do partido político MPLA (Movimento Popular de Libertação de Angola) investiu um golpe de estado cuja designação ficou conhecida como Fraccionismo, período que durou dois anos, sob a liderança de Nito Alves contra o poder que estava nas mãos da esfera política do restante do MPLA. Na trama, Pedro Gouveia e sua família são perseguidos e torturados pelos líderes contrários ao Fraccionismo, em particular pelo personagem (sugestivo até mesmo na sua denominação) Edmundo Barata dos Reis "ex-agente do Ministério da Segurança do estado" (AGUALUSA, p. 157) ou como ele próprio se autodenomina: “ex-gente! Ex-cidadão exemplar. Expoente dos excluídos, excremento existencial, excrescência exígua e explosiva" (AGUALUSA, p. 157), que vê Pedro 
como um "agente do imperialismo" (AGUALUSA, p. 175), Edmundo ainda explica o momento histórico transmutado ficcionalmente:

-Aconteceu há muito tempo, não é verdade? No tempo das lutas. [...] A Revolução estava em perigo. Um bando de miúdos, uma cambada de pequeno-burgueses irresponsáveis, tentou tomar o poder pela força. Tivemos de ser duros. Não perderemos tempo com julgamentos, disse o Velho no seu discurso à Nação, e não perdemos. Fizemos o que havia a fazer. [...] O nosso trabalho era separar as laranjas boas das laranjas podres. (AGUALUSA, p. 176-177, grifo do autor)

Tal cena conflitante impulsiona o fato de Pedro Gouveia comprar uma identidade angolana anos depois, assim, suas ações na obra acham-se incrustadas à realidade politica de Angola, na busca de vencer esse passado, "purificando-se" dessas reminiscências ao enxergar uma possibilidade de futuro. Nessa perspectiva, tornam-se bastante válidas as palavras de Jacinto Prado Coelho (COELHO, 1983, p.21 apud MATA, 2006, p. 27): “O universo é homogêneo porque o fictício absorve, integra e transfigura o real, a personagem histórica transforma-se numa personagem de ficção".

O cenário bélico respirado em Angola por tantos anos conflui-se, dessa maneira, às vivências das personagens, suas memórias estão carregadas dessas agruras. O espaço é carregado de imagens dolorosas que ultrapassam as próprias fronteiras de Luanda, convergindo para o continente africano e de um modo mais geral a todos os recantos que guardam "lembranças" de disputas desumanas pelo poder, seja pela travessia de refugiados em zonas de fronteiras, seja pelos elementos presentes no próprio espaço como signos de um período tortuoso na história do país. Tais imagens são capturadas pelo personagem José Buchmann ao acompanhar os passos de Edmundo Barata dos Reis na sua sarjeta habitual de ruas vazias, de "prédios em ruínas, com as paredes picadas pelas balas" (AGUALUSA, p. 105), de um tanque velho enferrujado que serve de sombra ao velho ex-agente do Estado. 
Tal cenário configura o sentimento que Inocência Mata (2006) designou como "consciência histórica", já que através desses lampejos do passado é possível reviver tais passagens com uma compreensão mais lúcida sobre o presente, mais crítica, se assim se pode inferir. Além disso, o conflito bélico surge no enredo como um profundo marcador temporal, quando as memórias narradas incidem sobre o leitor em um movimento de desorientação diante da sucessão temporal da narrativa, isto é, defronte às rememorações dos personagens e seus passados "criados", bem como às lembranças da osga de sua vida anterior como humano, a memória de guerra estabelece uma "orientação", uma "bússola" em direção ao presente, e um guia mais claro sobre o próprio passado na sucessão dos fatos da narrativa, o que se estende ao contexto de Angola. É assim que, Inocência Mata analisa, ainda, a relevância do signo bélico na narrativa angolana: "É também a guerra que marca o ritmo da periodicidade, com a desestruturação social, a sua reordenação implicando reajustamentos de mentalidades e instituições, significadores importantes de mudanças dos ciclos históricos" (MATA, p. 81).

A despeito de ser a guerra um momento que conduz ao término de algo, uma contemplação do fim, como percebe Félix: "Era o fim, ou era quase o fim, só não se percebia de quê" (AGUALUSA, p. 61), ela proporciona em seu ensejo memorial uma densidade de visualização sobre a sociedade angolana. Essa última que viu desde a guerra colonial o começo de um ciclo de novos embates pela dominação do poder, em que cada nova luta repercutia um "novo" período, mas no âmago da questão concentravam-se as mesmas características em que a maioria da população perecia sob os desmandos de uma seleta parcela social que apenas revesou- se aos "brancos" no poder. Nessas circunstâncias, a guerra não marcaria o decreto de um final, mas sim um princípio de continuidades, ou seja, nesse caso a continuidade da política por meios violentos. 
Tal constatação é aflorada no romance pelos personagens que já se acostumaram ao momento bélico. De tal maneira que possuem até mesmo um otimismo improvável perante um panorama de características tão hostis, como por exemplo, a Velha Esperança, de denominação já tão simbólica nesse meio desolador, empregada da casa de Félix Ventura, que acredita sinceramente que não morrerá nunca por ter sobrevivido a um massacre nos idos de 1992 (época da guerra civil em Angola), ficando presa em um dos regimentos militares da oposição ao governo e no momento em que seria fuzilada faltaram balas, o que lhe salvou a vida e a faz acreditar que é imune à morte, o que segundo a osga - narrador: "Não me parece impossivel. Esperança Job Sapalalo tem uma fina teia de rugas no rosto, o cabelo todo branco, mas as carnes mantêm-se rijas, e os gestos são firmes e precisos. $\mathrm{Na}$ minha opinião, é a coluna que sustenta esta casa" (AGUALUSA, p.12).

No entanto, o se acostumar, descrito acima, não quer aqui indicar um conformismo nessas reflexões sobre o passado, pelo contrário, é ao tratar do passado, com a clareza de um olhar contundente e esclarecido, que se percebe a sua desvinculação de um sentimento de saudosismo, ou mesmo do sentimento de um passado glorioso. De acordo com as palavras de Inocência Mata:

Do que os autores falam é da necessidade de desocultação do passado, para o desdramatizar e, ao mesmo tempo, fazer passar a imagem da História, com a distância que o tempo proporciona, pelo desencanto e pela perda da inocência, para que esta, a imagem do passado, se transforme em realidade em que todos se reconheçam - não aquelas em que apenas existam consensos, mesmices, harmonia. (MATA, p. 43, grifo do autor)

Permite-se assim, uma visão elucidativa do processo de guerra com "cores" mais conscientes, não se rememora para chorar as mágoas de um passado sombrio, mas por esse fazer parte da história do povo angolano e, se fazer necessário entender como funciona a construção do 
momento que se vivi. Desse modo, observa-se nas obras "pós-coloniais": "escritas catárticas que reafirmam a necessidade de se discutirem temas incômodos estrategicamente rasurados das preocupações quotidianas da inteligentsia" (MATA,2001, p.85 apud MATA, 2006, p. 34, grifo do autor). Assim, é que se percebe essa natureza no trecho da desminagem ${ }^{5}$ descrita pela osga, revelando a consciência que se purifica desse passado de guerra por se falar dele claramente sem circunlóquios:

Neste país não falta trabalho aos sapadores. Ainda ontem vi, na televisão, uma reportagem sobre o processo de desminagem. Um dirigente de uma organização não governamental lamentou a incerteza dos números. Ninguém sabe, ao certo, quantas minas foram enterradas no chão de Angola. Entre dez a vinte milhões. Provavelmente haverá mais minas do que angolanos. (AGUALUSA, p. $10-11$ )

No final da trama, a função catártica da memória (comentada anteriormente por Mata) é sentida pela inversão realizada por um personagem inominável que deseja comprar um passado do vendedor Félix. Tal remissão encontra-se no capítulo sugestivo denominado de "O mascarado", no qual um homem sem nome, fatigado pelas lembranças, com fortuna para desfrutar, mas de quem roubaram até mesmo o rosto, inverte o jogo de passados ao requerer de Félix um passado simples, "um nome sem brilho", "uma genealogia obscura e irrefutável" (AGUALUSA, p. 186). Rompendo, assim, com a dinâmica da classe burguesa e "re-enraizando-se" à sua própria identidade por descobrir-se outro, como ele mesmo enxerga-se: “[...] comecei a desfrutar de uma sensação maravilhosa. Não sabia que nome lhe dar. Agora sei liberdade! Esta situação transformou-me num homem livre" (AGUALUSA, p. 186).

5 O contexto de desminagem é um processo concernente ao periodo de guerra em Angola, tal retrato é visto com mais acuidade no romance, também de Agualusa, Barroco tropical (2009) em que há o personagem inusitado Rato Mickey, representado a categoria dos sapadores (encarregados do trabalho com minas) na obra. 
É possível estabelecer a partir dessa "exorcização" do passado um olhar crítico sobre o próprio presente no universo literário de $O$ vendedor de passados (2004), no que tange a idéia de uma democracia fajuta. O que remontaria ao julgamento atual da realidade sobre o estado angolano de viver sob um regime ditatorial, pois se observa a persistência de um governo que coexiste a várias décadas no poder, sem que a população possa realmente desfrutar de liberdades e garantias democráticas. Esse olhar é trazido para o cerne da obra em vários momentos integrando-se à estrutura formal do texto e segue como pensamento reflexivo sobre Luanda, tendo em vista que a própria necessidade de se comprar um passado fantasioso instiga a percepção de uma sociedade que ainda não se encontrou, vivendo à margem da "superioridade branca", pois almejam uma genealogia do Outro', segundo a definição de Bonnici (2005) visto como o ser colonizador. Esse reflexo de um país de ficção, isto é, um país de uma democracia ainda fantasiosa, pode ser sentido nas letras a seguir a partir da fala do protagonista Félix Ventura: “- Temos então um presidente de fantasia -, disse enxugando as lágrimas com um lenço. - Isso eu já suspeitava. Temos um governo de fantasia. Um sistema judicial de fantasia. Temos, em resumo, um país de fantasia" (AGUALUSA, p. 160).

De um modo geral, a escrita de $O$ vendedor de passados (2004) realiza uma atividade que volta ao percurso histórico e repensa esse cenário que não se acha distanciado da forma como o romance está estruturado. A memória que serve de "guia" para esse percurso integra-se ao romance e age no modo como este se apresenta esteticamente. Assim, é que o elemento memorial demonstra, na obra, como literatura e sociedade se relacionam, sendo que o recorte histórico

${ }^{6}$ Bonnici determina o termo Outro com letra maiúscula para designar a entidade colonizadora, à figura europeia em outras palavras, quanto ao ser colonizado o autor utiliza o termo outro com letra minúscula. Esse conceito pode ser percebido na obra inserida na referência a seguir: BONNICI, Thomas \& ZOLIN, Lúcia Osana. Teoria Literária: abordagens históricas e tendências contemporâneas. Maringá: EDUEM, 2005. 
ganha amplitude, contudo não esvazia o sentido ficcional, que ganha nesse sentido até mais força pelo engajamento social que sugere o trabalho metafórico de Félix Ventura, exortando até mesmo um olhar metaficcional (além da consideração de uma metaficção historiográfica, conceito já contemplado anteriormente nesse artigo) na acepção do "ofício literário" de Félix ao armar enredos para as genealogias de seus clientes, dentre eles o personagem Ministro para quem Félix cria além de um "novo" passado, um livro, "um denso volume de memórias", ilustrando muito bem essa atitude criativa auto-reflexiva no texto:

Félix costura a realidade com a ficção, habilmente, minuciosamente, de forma a respeitar datas e factos históricos. O Ministro dialoga no livro com personagens reais (em alguns casos com Personagens Reais) e convém que tais personagens, amanhã, acreditem que trocaram com ele, realmente, confidências e pontos de vista. (AGUALUSA, p. 139)

Nessa altura, cabe considerar a relação do vendedor Félix com um griot, essa entidade africana de fundamental relevância para a constituição da história, pois este se encarrega de conservar a memória, tida como conhecimento fundamental para a comunidade africana. $\mathrm{O}$ griot é tratado com profunda reverência pelo povo africano, faz parte da cultura e assim, da tradição. O griot na cultura africana caracteriza-se como o contador de histórias, função que, segundo as noções de A. Hampaté Bá em seu livro Metodologia e pré-história da África (1970) é designada ao ancião de um determinado clã, ou melhor, tribo por sua sabedoria e capacidade na transmissão de conhecimento.

Desta maneira, Félix Ventura ironicamente cria passados que quebram com a história africana em nome da aspiração da sociedade burguesa de genealogias que moldem-se ao modelo do colonizador e não à lembrança do colonizado. No entanto, Félix tal qual o griot retrata o 
salvaguardar da memória profunda pautada na compreensão do tempo, principalmente do tempo em que se vivi em sua relação com o espaço.

Uma vez investido desses múltiplos olhares sobre a obra, chegase à visão crítica de Agualusa ao adentrar no passado e dele reviver a necessidade de uma identidade angolana que se falseia nas memórias criadas ao estilo do colonizador. Não obstante, o jogo da diversidade de vozes na narrativa desperta a crítica contra essa visão, o que é ouvido na voz do albino que se diz negro - Félix Ventura -, do forasteiro que revela seu passado de guerra - José Buchmann -, do militante Edmundo Barata dos Reis, da Velha Esperança, da osga-narrador Eulálio e suas memórias reencarnadas, enfim da multiplicidade que se faz audivel no "barco cheio de vozes" de Félix Ventura. O próprio protagonista confessa afinal, como se vê em sua atividade criativa: “Acho que aquilo que faço é uma forma avançada de literatura -, confidenciou-me, - Também eu crio enredos, invento personagens, mas em vez de os deixar presos dentro de um livro dou-lhes vida, atiro-os para a realidade" (AGUALUSA, p. 75).

A obra O vendedor de passados (2004) constitui uma vasta compilação de memórias que se engendram na estrutura do texto, constituindo a maneira singular em que o próprio ato de narrar é conduzido. Incita reminiscências substanciais do panorama histórico de Angola, permitindo compreender e analisar com mais perspicácia o presente ao apropriar-se de personagens e fatos do contexto historicista. Nessa leitura crítica, não se abandona o olhar estético, já que esse dialoga com o contexto sócio-político de forma veemente, permitindo através de um alegórico "vendedor de passados" uma visita à memória angolana e uma compreensão mais clara desta em sua complexidade por envolver o olhar reflexivo sobre a vida angolana numa linguagem de cunho inventivo que cria uma "nova" Luanda, uma projeção futura mais consciente de si, imaginada por um vendedor de passados. 


\section{Referências bibliográficas}

AGUALUSA, José Eduardo. O vendedor de passados. Rio de Janeiro: Gryphus, 2004.

- Entrevistado por Carlos Vaz Marques. In: Revista Ler Livros e leitores. Portugal, 2009 -, mensal. Disponivel em: http:/ / www.afonsopacheco.com/joomal/images/phocadownload/barro co_tropical/01.05\%20Revista\%20Ler\%2020Entrevista.pdf?ml=5\&mlt=sy stem\&tmpl=component. Acesso 10 mar. 2011.

BONNICI, Thomas \& ZOLIN, Lúcia Osana. Teoria Literária: abordagens históricas e tendências contemporâneas. Maringá: EDUEM, 2005.

CANDIDO, Antonio. Literatura e sociedade: estudos de teoria e história literária. 5 ed. São Paulo, Editora Nacional, 1976.

FANON, Frantz. Pele negra máscaras brancas. Trad. Adriano Caldas. Rio de Janeiro: Fator, 1983. (Coleção Outra gente, v. 1)

HAMPÂTÉ BÁ, Amadou. A tradição viva. In. Introdução à cultura Africana. Edições 70. Lisboa. 1970.

MATA, Inocência. Laços de memória e outros ensaios angolanos sobre literatura angolana. Luanda: União dos Escritores Angolanos, 2006.

SCHWARZ, Roberto. Pressupostos, salvo engano, de "Dialética da malandragem”. In: Que horas são? : ensaios. São Paulo: companhia das Letras, 1987. 
SILVA, Vitor Manuel de Aguiar e. Teoria da literatura. 8 ed. 10. reimp. Coimbra, Portugal: Almedina, 1997. (v. I). 